\title{
The Importance of Developmental Science for Studies in Bullying and Victimization
}

\author{
Peter K. Smith* and Alice P. Jones* \\ Department of Psychology, Goldsmiths College, University of London, London, UK
}

\begin{abstract}
Research on bullying and victimization, especially in school settings, has become an important area of developmental research, with strong practical implications. In this article we overview some considerations from neuropsychology, quantitative genetics, developmental neuroscience, we discuss CU traits and conduct problems, individual, group, class and school levels of analysis, developmental changes by age and context, and cross-cultural aspects. Together we argue that these can help bring about a developmental science perspective on to this area of research.
\end{abstract}

Keywords

bullying, victimization, aggression, school

Over the last 30 years, research on bullying and victimization, especially in school settings, has expanded very considerably; it can now be considered as an established international research program (Smith, 2011). It takes as a core concept that bullying refers to repeated and intentional aggressive acts, together with some imbalance of power (Olweus, 1993). Earlier research focussed on the nature and frequency of such behaviours, participant roles in bullying, age and gender differences, and other correlates; together with some practical focus on school-based interventions. There has subsequently been more emphasis on longitudinal studies (e.g., Reijntjes, Kamphuis, Prinzie, \& Telch, 2010; Ttofi, Farrington, Lösel, \& Loeber, 2011) and on the study of risk and protective factors (e.g., Cook, Williams, Guerra, Kim, \& Sadek, 2010). Here we overview conceptual and methodological considerations across a range of areas, that can help bring about a developmental science perspective on to this

\footnotetext{
*Address for correspondence

Peter K. Smith and Alice P. Jones are at the Unit for School and Family Studies, Department of Psychology, Goldsmiths College, New Cross, London SE14 6NW, UK. E-mails: p.smith@gold.ac.uk, a.jones@gold.ac.uk
}

lively and socially important area of research, and help it move further from the more descriptive studies, to an understanding of a complex network of risk and protective factors involved in both bullying others, and of being a victim of bullying.

\section{Neuropsychological Aspects}

A body of research has developed with the aim of helping to identify children who are at risk of becoming bullies or victims of bullying. Studies suggest that lower levels of prosocial or co-operative behaviours are associated with bullying (Smith, Polenik, Nakasita, \& Jones, 2012), while others have posited lower levels of empathy (Jolliffe \& Farrington, 2011). Children who have been peer-nominated as bullies have also been reported to have neuropsychological deficits in the domain of executive functions (e.g., Coolidge, Den Boer, \& Segal, 2004). However, it is important to keep in mind that findings in this field have been mixed, and it will be worth continuing research in this area focusing on different sub-groups of bullies, as well as different profiles over time. Despite these avenues for future research, 
a neuropsychological deficit account of bullying may suggest that interventions need to focus on ameliorating these deficits as well as working on improving social relationships.

\section{Quantitative Genetic Investigations}

Many studies have contributed to the profiles of children who bully, or who are victimised, using cross-sectional and longitudinal methods to examine the associations between family functioning and bullying behaviours. However, pulling apart the causal influences of genes or environment on bullying is still a relatively new area of investigation. Using genetically sensitive methodologies to think about the relative influences of nature and nurture on bullying is important - we can not make assumptions about either from simple familial associations because genetic and environmental contributions are often confounded (Plomin, DeFries, McClearn, \& McGuffin, 2008).

One such genetically informative study examined the genetic and environmental influences on bullying and victimisation in a sample of over 1,000 twinpairs aged between seven and ten years (Ball et al., 2008). The majority of the variance for both bullying and victimisation was explained by genetic influences, with non-shared environmental factors contributing toward to the remainder. These findings suggest that a child's genetic make-up, as well as its raising environments, influence involvement in bullying, as bully or victim.

\section{Developmental Neuroscience}

Recent work in neuroscience has begun to allow an insight into the experiences of those who experience social rejection or victimization. Social pain has been suggested to activate similar neural networks as activated by physical pain (Eisenberger \& Lieberman, 2007), and so 'hurt feelings' may be an accurate description of the experiences of victims of bullying. Studies have also linked greater activation in brain areas associated with social rejection (e.g., regions of the anterior cingulated cortex and ventral striatum) with greater reported distress at social rejection (Masten et al., 2009). Victimization has long been associated with poor mental health outcomes, and understanding the mechanisms by which this might occur is likely to have potential for effective treatment.

\section{CU Traits and Conduct Problems}

One group of children who may be better understood through knowledge of their neural processing styles are those children characterised by presence of elevated levels of callous-unemotional traits $(\mathrm{CU})$. CU traits index a particularly serious form of behavioural disturbance and include such characteristics as lack of guilt and empathy, commensurate with clinical descriptions of adult psychopathy. It is likely that children with CU cause some of the greatest and most prolonged disruption in a classroom and have also been suggested to play a role in bullying behaviours (Muñoz, Qualter, \& Padgett, 2011; Viding, Simmonds, Petrides, \& Frederickson, 2009).

\section{The Individual, Group, Class, and School}

From the work of Salmivalli and colleagues in the 1990 s (see Salmivalli, 2010) we know that bullying is very often a group process, even if bully-victim dyads form a central component. The social context of bullying is being developed in two ways, one related to processes and one related to interventions. At a process level, social identity theory has been used to argue that pupils will view other persons as belonging either to the in-group (their own group, viewed in favourable terms) or an out-group (another group, perceived more negatively), such that children's attitudes towards bullying can be moderated by in-group norms and perceived threat to group distinctiveness (e.g., Nesdale et al., 2008). These studies have generally used artificial scenarios or group assignments, but they do throw some light on determinants of attitudes and the importance of group pressures.

At a methodological level, we can conceive of the individuals or small groups involved in bully-victim relationships, as being embedded in a class structure, and classes themselves being embedded in a whole school. This is important when examining schoolbased interventions, which can operate at whole-school, whole-class, group or individual levels (Wölfer, Bull, \& Scheithauer, 2011). Multi-level modelling procedures allow some examination of these separate impacts.

\section{Developmental Changes, Age, and Context}

Most research on bullying has focussed on the 8 to 16 year age range, namely school children who are old 
enough to fill in questionnaires. In recent years there has been more focus on younger children, and the origins of bullying-like behaviours in preschool and the infant school years. Although not necessarily fulfilling all the definitional criteria of bullying, nevertheless such research can help develop theoretical perspectives on how bully-victim relationships develop a few years later (Monks, 2011).

Cyberbullying, which refers to the use of mobile phones and the internet to bully others, has increased dramatically in the last decade. Cyberbullying leads to some new perspectives on age and context. Even at school age, much cyberbullying takes place outside school, and although it often involves peers this need not be the case. For traditional bullying, studies of workplace bullying differ from those of school bullying both in terms of developmental age, and context (school/workplace). The cyber world provides a common context, largely independent of school or workplace, and may provide an opportunity to look more directly at developmental changes in a lifespan perspective (Smith, 2010).

\section{Cross-Cultural Aspects, Language, and Behaviour}

The origins of western research on bullying and victimization were in Scandinavia, spreading fairly rapidly to other European countries, North America and Australasia. A separate research tradition on ijime existed in Japan since at least the 1980 s. Ijime in Japan, and wang-ta in South Korea, are phenomena similar to bullying, but with some differences, mainly relating to an increased salience of group processes and social exclusion in these traditionally more collectivist societies (Lee, Smith, \& Monks, 2011).

Cross-national comparisons of bullying rates (e.g., Elgar et al., 2009) can be important, but need to take consideration of linguistic issues, as bullying-related terms in different languages do not have identical meanings. An important area of study is whether crossnational differences reflect different understandings of what bullying is, or different kinds of behaviours, or both.

\section{Conclusions}

Research in the field of developmental science has contributed greatly to our understanding of bullying and victimisation. However, there are still clearly some developing areas to consider. We might ask whether developmental cognitive neuroscience can help to better understand the factors that might make a child vulnerable to becoming a bully or a victim? Can we then develop tailored interventions that meet the specific needs and neuro-cognitive profiles of these children? Can we successfully integrate approaches that bear on individual, group, class and school level factors, bearing in mind the social and cultural context? Can we develop a fuller life-span perspective on bullying and victimization, rather than having separate fields of school bullying and workplace bullying? Can cross-cultural studies give us better insight into the relationship between language and behaviour, and the variation in bullying processes? A fuller integration of this research program will undoubtedly benefit from interdisciplinary studies, combining biological, developmental, group psychological, and cross-cultural approaches. Accordingly, a developmental science perspective on to this area of research is necessary.

\section{References}

Ball, H. A., Arsenault, L., Taylor, A., Maughan, B., Caspi, A., \& Moffitt, T. E. (2008). Genetic and Environmental influences on victims, bullies and bully-victims in childhood. Journal of Child Psychology and Psychiatry, 49, 104-112.

Cook, C. R., Williams, K. R., Guerra, N. G., Kim, T. E., \& Sadek, S. (2010). Predictors of bullying and victimization in childhood and adolescence: A meta-analytic investigation. School Psychology Quarterly, 25, 65-83.

Coolidge, F. L., Den Boer, J. W., \& Segal, D. L. (2004). Personality and neuropsychological correlates of bullying behavior. Personality and Individual Differences, 36, 1559-1569.

Eisenberger, N. I., \& Lieberman, M. D. (2007). fMRI responses relate to differences in real-world social experience. Emotion, 7, 745754.

Elgar, F. J., Craig, W., Boyce, W., Morgan, A., \& Vella-Zarb, R. (2009). Income inequality and school bullying: Multilevel study of adolescents in 37 countries. Journal of Adolescent Health, 45, 351-359.

Jolliffe, D., \& Farrington, D. P. (2011). Is low empathy related to bullying after controlling for individual and social background variables? Journal of Adolescence, 34, 59-71.

Lee, S.-H., Smith, P. K., \& Monks, C. (2011). Perception of bullyinglike phenomena in South Korea: A qualitative approach from a lifespan perspective. Journal of Aggression, Conflict and Peace Research, 3, 210-221.

Masten, C. L., Eisenberger, N. L., Borofsky, L. A., Pfeifer, J. H., McNealy, K., Mazziotta, J. C., \& Dapretto, M. (2009). Neural correlates of social exclusion during adolescence: Understanding the distress of peer rejection. Social, Cognitive and Affective Neuroscience, 4, 143-157.

Monks, C. P. (2011). Peer victimisation in preschool. In C. Monks, \& I. Coyne, (Eds.), Bullying in different contexts (pp. 12-35). Cambridge: Cambridge University Press. 
Muñoz, L. C., Qualter, P., \& Padgett, G. (2011). Empathy and bullying: Exploring the influence of callous-unemotional traits. Child Psychiatry and Human Development, 42, 183-196.

Nesdale, D., Durkin, K., Maass, A., Kiesner, J., \& Griffiths, J. A. (2008). Effects of group norms on children's intentions to bully. Social Development, 17, 889-907.

Olweus, D. (1993). Bullying at school: What we know and what we can do. Oxford: Blackwell.

Plomin, R., DeFries, J. C., McClearn, G. E., \& McGuffin, P. (2008). Behavioral genetics. 5th edition. New York, NY: Worth Publishers.

Reijntjes, A., Kamphuis, J. H., Prinzie, P., \& Telch, M. J. (2010). Peer victimization and internalizing problems in children: A meta-analysis of longitudinal studies. Child Abuse \& Neglect, 34, 244-252.

Salmivalli, C. (2010). Bullying and the peer group: A review. Aggression and Violent Behavior, 15, 112-120.

Smith, H., Polenik, K., Nakasita, S., \& Jones, A. P. (2012). Profiling social, emotional and behavioural difficulties according to bullying subtype. Emotional and Behavioural Difficulties, 17, in press.

Smith, P. K. (2010). Cyberbullying: The European perspective. In J. A. Mora-Merchán \& T. Jäger (Eds.), Cyberbullying. A crossnational comparison (pp. 7-19). Landau: Verlag Empirische Pädagogik.

Smith, P. K. (2011). Bullying in schools: Thirty years of research. In Monks, C. \& Coyne, I. (Eds.), Bullying in different contexts (pp. 36-60). Cambridge: Cambridge University Press.

Ttofi, M. M., Farrington, D. P., Lösel, F., \& Loeber, R. (2011). The predictive efficiency of school bullying versus later offending: A systematic/meta-analytic review of longitudinal studies. Criminal Behaviour and Mental Health, 21, 80-89.
Viding, E., Simmonds, E., Petrides, K. V., \& Frederickson, N. (2009). The contribution of callous-unemotional traits and conduct problems to bullying in early adolescence. Journal of Child Psychology and Psychiatry, 50, 471-481.

Wölfer, R., Bull, H. D., \& Scheithauer, H. (2011). Social integration in youth: Insights from a social network perspective. Group Dynamics: Theory, Research, and Practice. doi: 10.1037/ $\mathrm{a} 0024765$.

\section{Bio Sketches}

Peter K. Smith is Emeritus Professor of Psychology at the Unit for School and Family Studies, Goldsmiths, University of London, U.K. He is co-editor of "CyberBullying in the Global Playground: Research from International Perspectives" (Wiley-Blackwell, 2012), and Chair of COST Action IS0801 on "Cyberbullying: coping with negative and enhancing positive uses of new technologies, in relationships in educational settings".

Alice Jones is the Head of the Unit for School and Family Studies at Goldsmiths, University of London. Her research takes a multidisciplinary approach to behavioural and emotional difficulties that have a negative impact on learning. She is currently involved in investigating neuropsychological correlates of children and adolescents who have been excluded from mainstream education. 